\title{
Article \\ Should the Endoscopic Restrictions during COVID-19 Pandemic Remain Unchanged?
}

\author{
Emilio Bresky ${ }^{1}{ }^{1}$, Gustavo Bresky ${ }^{2,3, *}$, Domingo Lancellotti ${ }^{4}$, Juan Madariaga ${ }^{2,5}$, Sebastian Licuime ${ }^{1}$, \\ Paulette Palma ${ }^{1}$, Fabian Saez ${ }^{1}$ D , Maria Jose Rojas ${ }^{3,5}$ and Luis Seijas ${ }^{3,6}$ \\ 1 Faculty of Medicine, Universidad Católica del Norte, Coquimbo 1720506, Chile; \\ ebreskygomez@gmail.com (E.B.); sebastian.licuime@alumnos.ucn.cl (S.L.); \\ paulette.palma@alumnos.ucn.cl (P.P.); fabiansaezbarraza@gmail.com (F.S.) \\ 2 Department of Biomedical Sciences, Faculty of Medicine, Universidad Católica del Norte, \\ Coquimbo 1781421, Chile; madariaga@ucn.cl \\ 3 Endoscopy Unit, Centro Clínico Mediterráneo, La Serena 1720506, Chile; mjrojasflores@gmail.com (M.J.R.); \\ lucho.seijas@yahoo.es (L.S.) \\ 4 Department of Public Health, Faculty of Medicine, Universidad Católica del Norte, Coquimbo 1781421, Chile; \\ dlancell@ucn.cl \\ 5 Endoscopy Unit, Hospital de Coquimbo, Coquimbo 1700000, Chile \\ 6 Endoscopy Unit, Hospital de La Serena, La Serena 1710216, Chile \\ * Correspondence: bresky@ucn.cl
}

Citation: Bresky, E.; Bresky, G.; Lancellotti, D.; Madariaga, J.; Licuime, S.; Palma, P.; Saez, F.; Rojas, M.J.; Seijas, L. Should the Endoscopic Restrictions during COVID-19

Pandemic Remain

Unchanged? Gastroenterol. Insights 2021, 12, 358-365. https://doi.org/ $10.3390 /$ gastroent12030034

Academic Editors: Chien-Feng Li, Ching-Chieh Yang and

Nai-Jung Chiang

Received: 21 July 2021

Accepted: 23 August 2021

Published: 25 August 2021

Publisher's Note: MDPI stays neutral with regard to jurisdictional claims in published maps and institutional affiliations.

Copyright: (c) 2021 by the authors. Licensee MDPI, Basel, Switzerland. This article is an open access article distributed under the terms and conditions of the Creative Commons Attribution (CC BY) license (https:/ / creativecommons.org/licenses/by/ $4.0 /)$.
Abstract: (Background) Endoscopic procedures are interventions that have been defined as carrying a high-risk of infection with COVID-19. Most endoscopy units restrict their activity based on pre-endoscopic diagnosis. (Objective) To determine the consequences of endoscopic restrictions as a result of the COVID-19 pandemic and their impact on digestive cancer diagnosis. (Design) A comparison of upper digestive endoscopies and colonoscopies with gastrointestinal cancers diagnosed between three endoscopic centers, two of which restricted their procedures and one that did not but performed the procedures under a strict protocol. (Setting) A retrospective analysis was performed collecting data between 15 March 2019 and 15 August 2020. Two-factor ANOVA and a Tukey's a posteriori test were used as statistical tests. (Main outcome measures) There was variation in gastrointestinal cancer diagnosis between 2019 and 2020, considering the endoscopic procedures performed each year. (Result) There was a significant decrease in the total endoscopic procedures performed between 2019 and $2020(p<0.001)$, the result of reduced testing at the two centers $(p<0.001)$ with pre-endoscopic restrictions, which was not compensated for by a slight increase in procedures at the center without restrictions $(p=0.139)$. Regarding the total cancers diagnosed, while a significant decrease was observed for the two centers with pre-endoscopic restrictions $(p=0.007)$, a significant increase was registered in the center that maintained its endoscopic productivity $(p<0.001)$. After 851 procedures (537 upper digestive endoscopies and 314 colonoscopies) there was no evidence of COVID-19 infection in the endoscopic staff. (Conclusion) Endoscopic restrictions based on preendoscopic diagnosis should be reassessed in consideration of local pandemic situations, and a balance should be sought between COVID-19 infection risk and the detrimental delay of potential cancer diagnosis.

Keywords: endoscopy; gastrointestinal; coronavirus infections; gastrointestinal neoplasms; stomach neoplasms; colorectal neoplasms

\section{Introduction}

The COVID-19 pandemic produced a radical change in various aspects of our lives. This virus can be transmitted directly from both symptomatic and asymptomatic patients [1] from less than one meter [2] through respiratory droplets, then establish contact with the oral mucosa or nasal or conjunctiva [3]. The virus can also survive for a restricted 
amount of time on different surfaces, which means that infection can also be acquired indirectly through contact with contaminated surfaces [4]. Additionally, there is some evidence that the virus can cause intestinal infection and be excreted in the feces [5]. The airborne spread of the virus is especially important in certain procedures that can generate aerosols, such as intubation, bronchoscopy, and upper gastrointestinal endoscopy [6,7]. This has led to the definition of all endoscopic procedures as high risk for COVID-19 infection. Both health authorities and most gastroenterological scientific societies worldwide have recommended cancelling endoscopic procedures, except in cases of emergency [6]. Under this logic, the Asociación Chilena de Endoscopia Digestiva (ACHED) released recommendations in March 2020 indicating that the realization of endoscopy procedures should be based on pre-endoscopic clinical diagnosis (PreDg); in other words, that they be performed only in cases of upper gastrointestinal bleeding, lower gastrointestinal bleeding, foreign body removal, sigmoid volvulus, priority diagnostic colonoscopy (e.g., when there is a high suspicion of ulcerative colitis), installation of nasojejunal tube, installation of percutaneous endoscopic gastrostomy, diagnostic and/or therapeutic oncology (defined by each team), a varicose vein ligation program (case-by-case evaluation) or a stenosis dilation program (case-by-case evaluation) [8]. However, this recommendation to delay elective procedures and perform only emergency procedures may lead to a delay in the diagnosis of various digestive neoplasms, which could result in reduced survival. A British study using a theoretical model suggested that delay in the diagnosis of several cancers (including colon, rectum, esophagus and stomach) negatively impacts the survival of these cancer patients. It is possible that a three-month delay could result in a reduction of more than $10 \%$ long-term survival (10 years), or in cases of of six-month delays, more than $30 \%$ [9]. In Chile, the first confirmed case of COVID-19 was reported on 3 March 2020 [10]. Our country has more than 19 million inhabitants distributed over $775.776 \mathrm{~km}^{2}$, with a high population density in the Metropolitan Region $(8,125,072$ inhabitants). The Centro Clínico Mediterráneo (CCM), located in the City of La Serena (Coquimbo Region), has a private ambulatory endoscopy unit that provides services to the citizens of La Serena, and the Coquimbo whose population is almost 450,000 [11]. In these two cities, there are a total of four endoscopic ambulatory centers (which exclusively provide outpatient care) and three mixed centers (for both outpatient and in-hospital patients), including a private clinic and two public hospitals). The hospitals are the endoscopic units with the highest endoscopic productivity in the region. As endoscopic procedures are considered to possess high risk for COVID-19 infection, the endoscopy services of the public health network have performed only urgent procedures since March 2020. The remaining endoscopic centers of La Serena and Coquimbo decided to halt their operation in the second half of March 2020 based on the same criteria. The only regional exception was the CCM, where the staff analyzed the epidemiological situation not only of the country but also of the Coquimbo Region, as there were important differences in the rates of confirmed cases of COVID-19 patients per 100,000 inhabitants between the entire country, the Metropolitan Region, and the Coquimbo Region (Figure 1). All personnel were given the option of stopping operations entirely or to continuing working with modified protocols to reduce the risk of infection. Initially, a single endoscopist and his group of assistants continued working, but after a few weeks the remaining endoscopists gradually rejoined. The CCM then became the only endoscopic unit in the region that continued performing upper endoscopies and colonoscopies without exclusions based on a pre-endoscopic diagnosis. Although there were no exclusions, several adaptations were made in order for the clinical center and the endoscopic unit to continue operating, and these adaptations are described in the Material and Methods section (see "Protocol of modifications in CCM" in Section 2). 


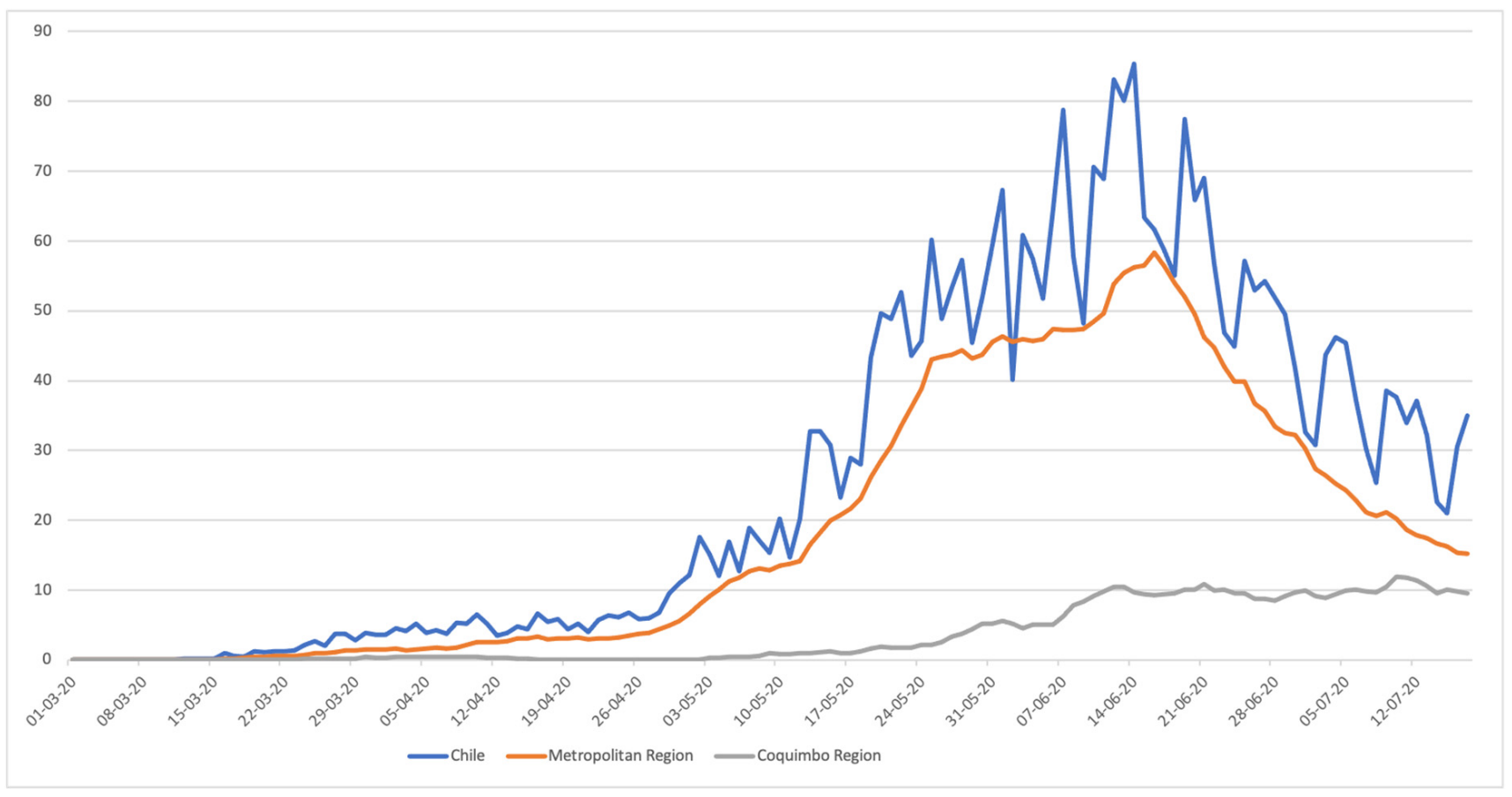

Figure 1. Evolution of confirmed cases of COVID-19 per 100,000 inhabitants. Source: own elaboration based on data from the Ministry of Health.

\section{Materials and Methods}

Endoscopic procedures and digestive cancer diagnosis data were studied in three centers: two public hospitals, Hospital de La Serena (HLS) and Hospital de Coquimbo $(\mathrm{HC})$, and in the CCM, whose endoscopic unit is private and outpatient only. Information was collected on the type and number of all endoscopic procedures performed between 15 March and 15 August 2019 (P19), and between 15 March and 15 August 2020 (P20). It should be considered that for correct functioning during P20, CCM protocols had to be modified (see "Protocol of modifications in $\mathrm{CCM}^{\text {"). }}$. All digestive cancers diagnosed in each center were recorded during both periods. For the CCM, the information was obtained from the records of the pathological anatomy laboratory Centro de Diagnóstico de Anatomía Patológica, while in the case of hospitals it was obtained from the Servicio Regional de Anatomía Patológica of the Hospital de Coquimbo, which has biopsy records from both hospitals. With the data obtained, Excel tables of monthly averages of endoscopic procedures and esophageal, gastric and colorectal cancers were constructed in each center for both studied periods. Results were analyzed using two-factor ANOVA, using establishments $(n=3)$ and periods $(n=2)$ as the factors and $n=5$ months of records for each establishment and period in particular $(n=30)$. The ANOVA detected significant differences; therefore, a Tukey's a posteriori test was used to establish which groups were significantly different. During the pandemic study period (P20), an anti-COVID-19 IgA and IgM (Rapid COVID-19 TEST. HANGZHOU REALY TECH CO, LTD.; China/Luxus Lebenswelt $\mathrm{GmbH}$; Germany) was measured in the CCM on three different occasions, and an absence of COVID-19 symptoms was verified daily for all staff of the endoscopy unit.

The protocol of modifications in the CCM due to COVID-19 were as follows:

- Mandatory use of a mask when entering the center;

- Limitation on number of companions (only one per patient);

- Closure of the space above the reception desk, with isolation from the administrative staff;

- Modifications in the distribution of waiting room furniture to maintain a distance of $1.5 \mathrm{~m}$ between users; 
- Epidemiological surveys (see COVID-19 Survey, in Supplementary Materials) and temperature checks conducted for all patients;

- $\quad$ Endoscopy and ward cleaning teams were provided PPE and instructed regarding use (see "Protocol of PPE" below);

- Changes to endoscopic ward disinfection protocol, including disinfection of all surfaces with chlorinated substances $10 \mathrm{~min}$ after the end of the procedure;

- Change to the internal circulation of patients and companions (encouraging them to leave their room through the emergency side door);

- Manufacturing of air isolation boxes to prevent air circulation around a patient's head during high endoscopies. This box was made of plastic, is transparent, and has three holes-a small one wrapped in a plastic sleeve to enter the endoscope, another to adjust the patient's neck, and one for the arm of the endoscopy assistant (Figure 2);

- Upon entering the endoscopy ward, the patient maintained the use of a mask. In the case of upper digestive endoscopies, the mask was removed prior to the placement of the "air isolation box", and as soon as it is removed, the personal mask was reinstalled. During colonoscopies, it was worn during the entire procedure;

- Looking for potential COVID-19 infection, IgG and IgM antibodies were measured periodically against COVID-19 in the endoscopic and cleaning teams using a rapid test, with symptoms monitored daily among staff.
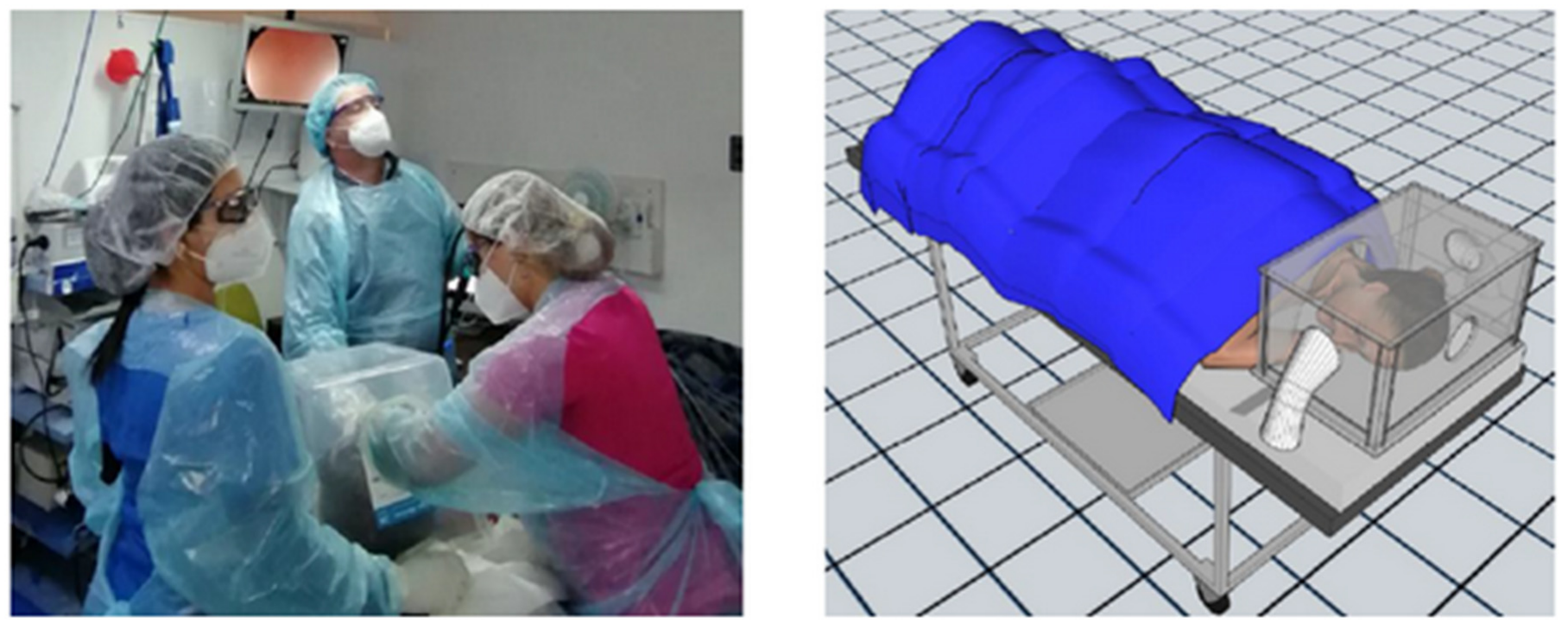

Figure 2. Design and use of an air isolation box due to the COVID-19 pandemic. Centro Clínico Mediterráneo.

\section{Protocol of PPE}

The use of a mask (surgical, N95 or any other similar certified by the ISP; use of N95 must be prioritized in procedures that generate respiratory aerosol [12]) was required, along with eye protection (goggles) or a face shield, a long-sleeved waterproof coat, a disposable waterproof apron and procedure gloves (one for each hand) [13].

The Chilean Society of Occupational Medicine also required the use of liquid soap, disposable towels, hydroalcoholic gel, surface disinfectant $(0.05 \%$ or $0.5 \%$ hypochlorite solution), a sharps disposal container, bags for hospital waste and mortuary bags [14].

Recommendations from the Chilean Medical College and Chilean Ministry of Health were followed in regards to the proper use and removal of PPE [13,15].

A container with a waterproof bag was required for the disposal of single-use PPE, which was discarded as "waste assimilable to household" or according to the Health Care Waste $(\mathrm{HCW})$ protocol of each establishment $[13,15]$. 


\section{Results}

The number of endoscopic procedures performed at HLS in P19 was 1012 (649 upper endoscopies and 363 colonoscopies; an average of 202 procedures per month); this decreased significantly in $\mathrm{P} 20$, with 183 procedures (108 and 75, respectively; an average of 37 procedures per month) $(p<0.001)$. The same trend was observed at HC, with 1016 procedures performed in P19 (758 upper endoscopies and 258 colonoscopies; an average of 203 procedures per month), but only 296 (179 and 117, respectively; an average of 59 procedures per month) performed during P20 $(p<0.001)$. At the CCM during the same periods, a total of 790 (485 upper endoscopies and 305 colonoscopies; an average of 158 procedures per month) and 851 (537 and 314, respectively; an average of 170 procedures per month) were performed in P19 and P20 ( $p=0.139)$, respectively (Figure 3).

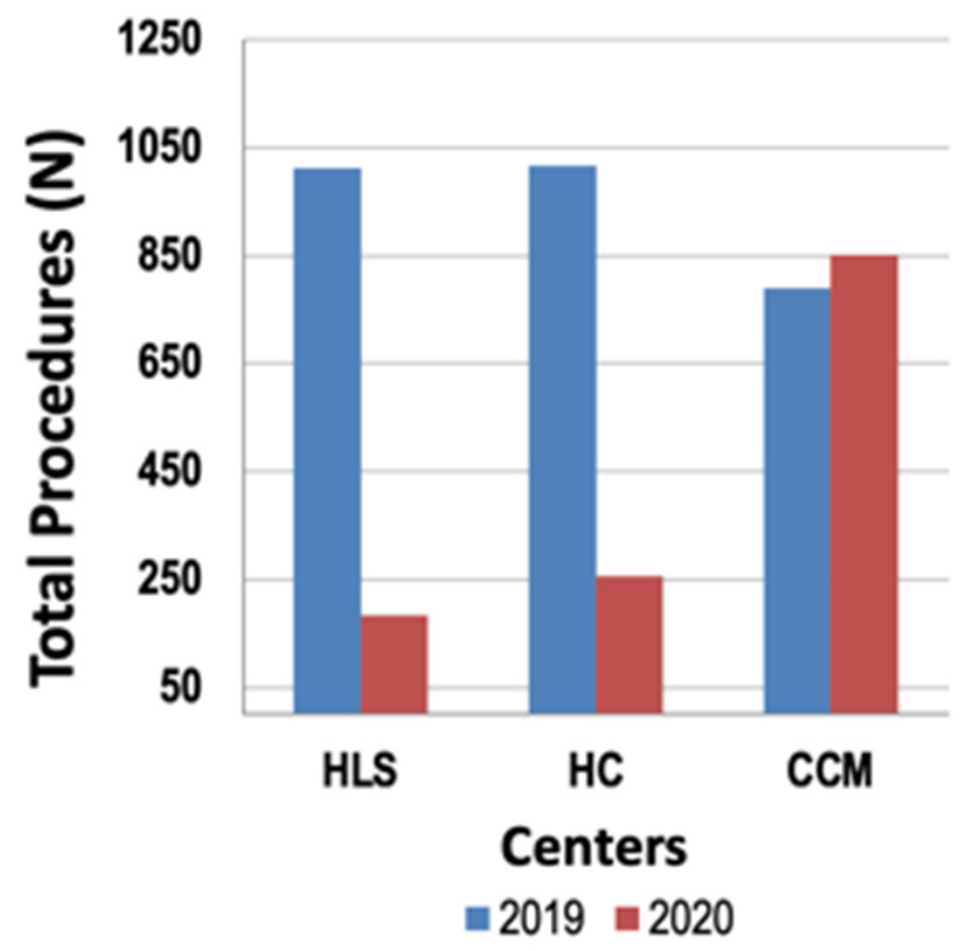

Figure 3. Total number of endoscopic procedures according to center and periods studied.

The overall number of digestive cancers registered during P19 and P20 showed significant decreases $(p<0.001)$ in the hospitals $(19$ to 9 diagnoses at HLS and 26 to 13 at $\mathrm{HC})$, while a significant increase was observed at CCM, from 3 to $22(p<0.001)$ (Figure 4). Likewise, these changes were also observed in colorectal cancer, with a significant decrease from 27 to 13 cases in hospitals with restrictions $(p<0.001)$ and a significant increase from 2 to 18 in the center without pre-endoscopic restrictions $(p<0.001)$. 


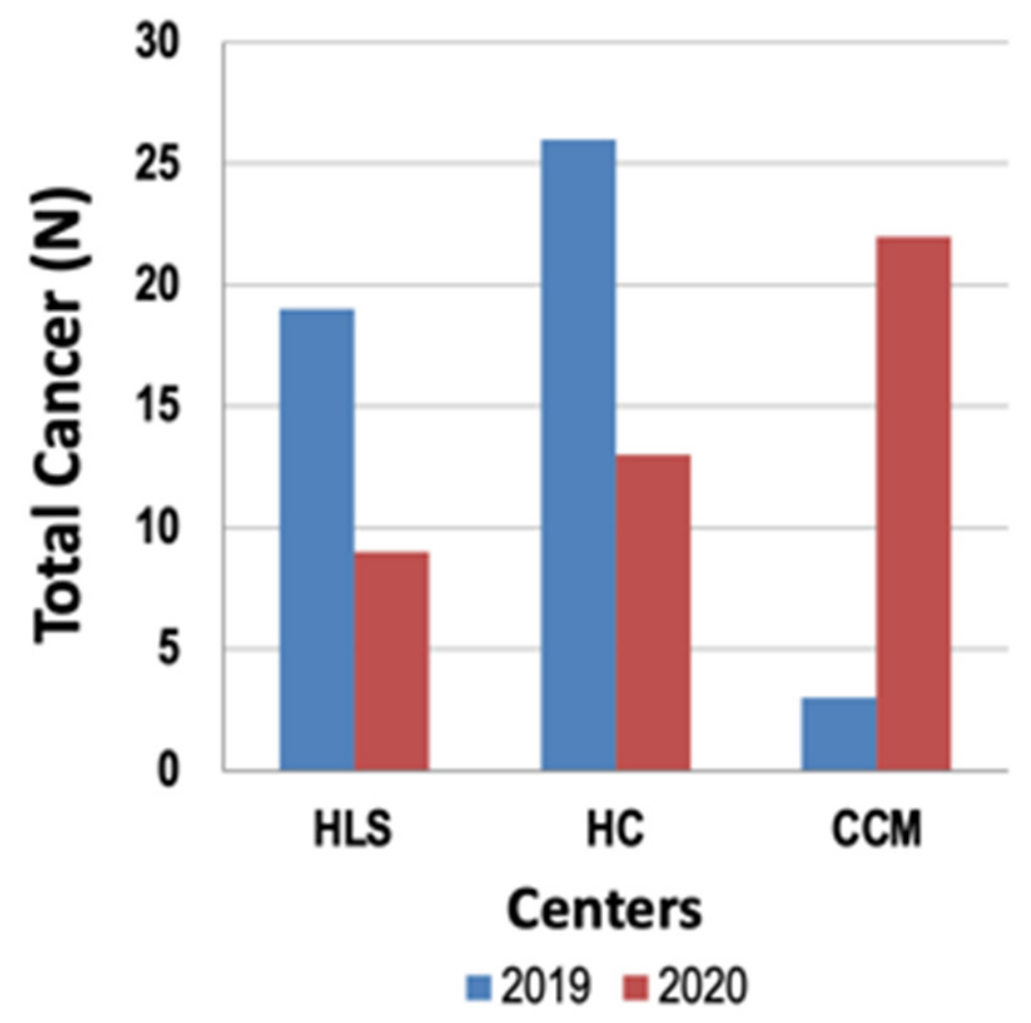

Figure 4. Total number of cancers diagnosed according to center and period studied.

COVID-19 symptoms were not found in any members of the CCM endoscopy staff during the entire pandemic period studied (P20), and none of the rapid test samples performed in the CCM endoscopy staff demonstrated an existence of anti-COVID-19 antibodies.

\section{Discussion}

The COVID-19 pandemic has necessitated the implementation of numerous measures in order to prevent the spread of infection within the population. Most of these actions have been supported by scant scientific evidence in the search for theoretical elements that could influence the possibility of being infected by the virus. As a result, scientific societies and health authorities defined a series of guidelines based on expert opinions [16-18]. As a result, endoscopies were defined as high-risk procedures (because they are aerosol generators) [6] and recommendations were released to restrict endoscopic activities among the vast majority of endoscopy units worldwide [6,18]. Most scientific societies have defined this restrictive measure based on PreDg, but have not considered regional infection rates during the determination of whether to implement restrictions [6]. Thus, the population requiring endoscopic studies has been divided into urgent and non-urgent, postponing the latter case indefinitely. Our study indicates that selection based on pre-endoscopic clinical diagnosis, which was used in both study hospitals, negatively impacted the ability to diagnose digestive neoplasms. Additionally, not restricting endoscopic procedures at the CCM not only increased the number of procedures performed during the COVID-19 pandemic, but also significantly increased the probability of diagnosing digestive cancers. The fact that the diagnosis of digestive cancers did not vary significantly between 2019 and 2020, even though it did increase significantly at the CCM, implies that this center absorbed a considerable part of the patients who were being neglected in public hospitals as a result of the pre-selection guidelines based on a pre-endoscopic diagnosis. If all the centers had followed this rule, the diagnosis of cancer in a significant number of people might have been significantly delayed. Based on predictive models, it is possible to infer that these 
people would have suffered an important negative impact on their life expectancy due to this delay in diagnosis [9]. It is to be expected that after the lifting of restrictive measures, endoscopy units and surgical wards will have serious difficulties in fulfilling the needs of the population, generating an increase in waiting lists for endoscopy and surgery, which, in turn, could have an even greater impact on the life expectancies of cancer patients. Another aspect to highlight in this study is that having established modified protocols by which to reduce the risk of infection in the CCM, health staff would have a reduced probability of COVID-19 contagion. After 851 procedures (537 upper gastrointestinal endoscopies and 314 colonoscopies), our team did not present any clinical evidence of COVID-19 infection, while all rapid tests (IgA and IgG anti-COVID-19) showed negative results. Within our COVID-19 prevention protocol, we believe that a fundamental element, in addition to all endoscopy unit personnel using PPE, is the use of the self-made air isolation box that we used with all our patients during upper endoscopies (see Figure 1). Despite this, the present study does not allow us to definitively conclude whether the protocols used to perform endoscopies prevented contagion, and to determine this would require another study. Finally, it is important to highlight that among the cancers diagnosed at the CCM, colorectal cancer was significantly increased. Another possible limitation of this study is the retrospective research condition, which did not allow the comparison of any of the variables between centres (such as the determination of IgM and IgG COVID-19 in the staff of the endoscopy units, or the use of the isolation box air for upper endoscopies in the two public hospitals included in the analysis). Based on the findings of our study, we recommend that preventive measures be maintained even in more favourable epidemiological conditions (e.g., the use of an air isolation box for upper endoscopies, the permanent use of PPE, the inclusion of capacity limits according to physical space, the promotion of social distancing with accurate instructions and signage, etc.). Along with this, we believe that selection criterion should be based on COVID-19 risk of infection (survey and temperature measurement) and should not be made according to pre-endoscopic clinical diagnosis.

\section{Conclusions}

Although there is evidence that COVID-19 patients can present the virus in fecal matter $[6,19]$, the infectivity of the colonoscopic procedure is probably low [6]; therefore, it is debatable whether to include colonoscopies within the pre-selection logic for endoscopic patients. In conclusion, restrictive measures of endoscopic activity based on pre-endoscopic diagnosis should be reviewed considering local rates of confirmed cases, and this should be based on the emerging evidence in order to find a balance between risk of COVID19 infection and the potentially detrimental delay of a cancer diagnosis (with a possible reduction in life expectancy) among those patients.

Supplementary Materials: The following are available online at https:/ / www.mdpi.com/article/10 .3390 /gastroent12030034/s1, COVID-19 Survey.

Author Contributions: Conceptualization, G.B.; methodology, E.B., G.B., D.L., S.L., P.P. and F.S.; software, D.L.; validation, G.B., D.L.; formal analysis, E.B., G.B., D.L., S.L., P.P. and F.S.; investigation, G.B.; resources, G.B., J.M., F.S., M.J.R., L.S.; data curation, D.L., J.M., F.S., M.J.R., L.S.; writing—original draft preparation, E.B., G.B.; writing-review and editing, E.B., G.B., S.L., P.P. and F.S.; visualization, E.B., G.B.; supervision, G.B.; project administration, G.B.; funding acquisition, E.B., G.B. All authors have read and agreed to the published version of the manuscript.

Funding: This research received no external funding.

Institutional Review Board Statement: The study was conducted according to the guidelines of the Declaration of Helsinki, and approved by the Ethics Committee of Universidad Católica del Norte (20 August 2020).

Informed Consent Statement: Patient consent was waived because the data (that was collected retroactively) has no personal information from patients. 
Data Availability Statement: If any data from this article is needed, do not hesitate to contact the corresponding author.

Conflicts of Interest: The authors declare no conflict of interest.

\section{References}

1. He, D.H.; Zhao, S.; Lin, Q.Y.; Zhuang, Z.; Cao, P.; Wang, M.H.; Yang, L. The relative transmissibility of asymptomatic COVID-19 infections among close contacts. Int. J. Infect. Dis. 2020, 94, 145-147. [CrossRef] [PubMed]

2. Siegel, J.D.; Rhinehart, E.; Jackson, M.; Chiarello, L. Health Care Infection Control Practices Advisory Committee. 2007 Guideline for isolation precautions: Preventing transmission of infectious agents in health care settings. Am. J. Infect. Control. 2007, 35, S65-S164. [CrossRef] [PubMed]

3. Riou, J.; Althaus, C.L. Pattern of early human-to-human transmission of Wuhan 2019 novel coronavirus (2019-nCoV), December 2019 to January 2020. Eurosurveillance 2020, 25, 2000058. [CrossRef] [PubMed]

4. Jones, C.L. Environmental surface contamination with SARS-CoV-2-A short review. J. Hum. Virol. Retrovirol. 2020, 8, 15-19. [CrossRef]

5. Xiao, F.; Tang, M.; Zheng, X.; Liu, Y.; Li, X.; Shan, H. Evidence for Gastrointestinal Infection of SARS-CoV-2. Gastroenterology 2020, 158, 1831-1833. [CrossRef] [PubMed]

6. $\quad$ Lui, R.N.; Wong, S.H.; Sánchez-Luna, S.A.; Pellino, G.; Bollipo, S.; Wong, M.; Chiu, P.W.Y.; Sung, J.J.Y. Overview of guidance for endoscopy during the coronavirus disease 2019 pandemic. J. Gastroenterol. Hepatol. 2020, 35, 749-759. [CrossRef] [PubMed]

7. Van Doremalen, N.; Bushmaker, T.; Morris, D.H.; Holbrook, M.G.; Gamble, A.; Williamson, B.N.; Tamin, A.; Harcourt, J.L.; Thornburg, N.J.; Gerber, S.I.; et al. Aerosol and Surface stability of SARS-CoV-2 as compared with SARS-CoV-1. N. Engl. J. Med. 2020, 382, 1564-1567. [CrossRef] [PubMed]

8. Díaz, A.; Cortés, P.; Heredia, C.; González, R.; Silva, V.; Bufadel, M.E.; Araya, R.J.; Moscoso, F.J.; Donoso, F.G.; Montenegro, C.U. Guía de recomendación ached-schge para el funcionamiento de las unidades de endoscopia durante el brote de coronavirus (COVID-19). Gastroenterol. Latinoam. 2020, 1, 9-20. [CrossRef]

9. Sud, A.; Torr, B.; Jones, M.E.; Broggio, J.; Scott, S.; Loveday, C.; Garrett, A.; Gronthoud, F.; Nicol, D.L.; Jhanji, S.; et al. Effect of delays in the 2-week-wait cancer referral pathway during the COVID-19 pandemic on cancer survival in the UK: A modelling study. Lancet Oncol. 2020, 21, 1035-1044. [CrossRef]

10. Ministerio de Salud (MINSAL). Situación Epidemiológica, COVID-19 Chile. 2020. Available online: https://www.minsal.cl/wpcontent/uploads/2020/03/Informe_3_COVID_19_Chile.pdf (accessed on 12 March 2020).

11. Instituto Nacional de Estadística (INE). Síntesis de Resultados CENSO 2017. 2017. Available online: https:/ / www.censo2017.cl/ descargas/home/sintesis-de-resultados-censo2017.pdf (accessed on 14 June 2020).

12. World Health Organization. Uso Racional de Equipo de Protección Personal Frente a la COVID-19 y Aspecto que Considerar en Situación de Escasez Graves. 2020. Available online: https://apps.who.int/iris/bitstream/handle/10665/331810/WHO-2019 -nCoV-IPC_PPE_use-2020.3-spa.pdf (accessed on 7 February 2020).

13. Colegio Médico de Chile. Recomendaciones uso de elementos de protección personal (EPP): Para trabajadores de la salud. Rev. Chil. Infectol. 2020, 37, 106-110. Available online: https:/ / scielo.conicyt.cl/scielo.php?script=sci_arttext\&pid=S0716-1018202000 0200106\&lng=es. (accessed on 3 March 2021). [CrossRef] [PubMed]

14. Sociedad Chilena de Medicina del Trabajo (SOCHMET). Pandemia por Coronavirus (COVID-19): Recomendaciones de Seguridad y Salud Ocupacional para Trabajadores de la Salud. 2020. Available online: http:/ /www.colegiomedico.cl/wp-content/uploads/ 2020/03/Recomendaciones-SOCHMET-Covid-19-para-trabajadores-de-la-salud-V01.pdf (accessed on 7 February 2021).

15. Subsecretaria de Redes Asistenciales (MINSAL). Protocolo de Referencia para Correcto uso de Equipos de Protección Personal en Pacientes Sospechosos o Confirmados de COVID-19. 2020, pp. 5-10. Available online: http://www.colegiomedico. cl/wp-content/uploads/2020/03/PROTOCOLO-DE-USO-DE-EQUIPOS-DE-PROTECCI\%C3\%93N-PERSONAL-EN-LAPREVENCI\%C3\%93N-DE-TRANSMISI\%C3\%93N-COVID19.pdf (accessed on 7 February 2021).

16. Castro, E.; Castro, R.; Fernandes, F.; Pereira, G.; Perazzo, H. Gastrointestinal endoscopy during the COVID-19 pandemic: An updated review of guidelines and statements from international and national societies. Gastrointest. Endosc. 2020, 92, 440-445. [CrossRef] [PubMed]

17. Chiu, P.W.Y.; Ng, S.C.; Inoue, H.; Reddy, D.N.; Hu, E.L.; Cho, J.Y.; Ho, L.K.Y.; Hewett, D.G.; Chiu, H.-M.; Rerknimitr, R.; et al. Practice of endoscopy during COVID-19 pandemic: Position statements of the Asian Pacific Society for Digestive Endoscopy (APSDE-COVID statements). Gut 2020, 69, 991-996. [CrossRef] [PubMed]

18. Gralnek, I.M.; Hassan, C.; Beilenhoff, U.; Antonelli, G.; Ebigbo, A.; Pellisè, M.; Arvanitakis, M.; Bhandari, P.; Bisschops, R.; Van Hooft, J.E.; et al. ESGE and ESGENA Position Statement on gastrointestinal endoscopy and the COVID-19 pandemic. Endoscopy 2020, 52, 483-490. [CrossRef] [PubMed]

19. Tian, Y.; Rong, L.; Nian, W.; He, Y. Review article: Gastrointestinal features in COVID-19 and the possibility of faecal transmission. Aliment. Pharmacol. Ther. 2020, 51, 843-851. [CrossRef] [PubMed] 